\title{
LAS FISGONAS DE PASO ANCHO LA ACTUALIZACIÓN DEL CORO Y LA RECUPERACIÓN DEL CHISME
}

\author{
LAS FISGONAS DE PASO ANCHO: BRINGING THE CHOIR \\ TO PRESENT AND RESCUING THE RUMOUR**
}

\section{Carolina Sanabria*}

\begin{abstract}
RESUMEN
El siguiente artículo tiene como propósito un abordaje de la obra dramática de Samuel Rovinski, Las fisgonas de Paso Ancho, desde el punto de vista de la estructuración de los personajes del título que funcionan como un replanteamiento del coro clásico griego. A partir de esta figura colectiva se propone una actualización desde el género de la comedia - propia de una comunidad rural, premoderna, pero asentada en la urbe- y considerando el desencadenante -la práctica comunicativa oral- que surge de un grupo marginal.

Palabras clave: coro, comedia, costumbrismo, actualización, chisme.
\end{abstract}

\begin{abstract}
**
The following article has the purpose of approaching Samuel Rovinski's play, Las fisgonas de Paso Ancho, from the characters' structure in the title, which function as a reconsideration from the classic Greek chorus. From this collective figure, I suggest rethinking it from the Comedy gender- as part of a rural and premodern community, but settled in the city-to consider what triggers it-the oral communicative practice- that arises from a marginal group.

Key Words: chorus, comedy, costumbrism, rethinking, gossip
\end{abstract}


Tras un renacimiento en la dramaturgia costarricense, Las fisgonas de Paso Ancho (1971) de Samuel Rovinski se inscribe en un primer período, de auge y crecimiento, gestado un par de décadas atrás (Quesada, 1997: 7). Se trata de una obra enmarcada en las políticas universitarias de extensión cultural que responde directamente a un programa de carácter popular -con tema, personajes y lenguaje pensados de antemano como identificables-, lo que habría de traducirse en una reactivación del teatro costarricense a raíz del aumento notable de espectadores que entonces acudieron a las salas (Bell y Fumero, 2000: 341).

Habiendo transcurrido más de 40 años de su estreno, la pieza de Rovinski merece una reconsideración para complementar la visión semiótica trabajada por los valiosos estudios de Vargas Vargas y Vásquez Vargas (1987) y de dicotomías de significación por Cortés (1988). En este caso la obra se contempla desde su contribución hacia otras vetas -las sociales, la revaloración de un discurso producido por una minoría- partiendo de la misma estructura dramática clásica -la figura del coro- en lo que Rovinski termina por plantear desde una dinámica reflexiva.

\section{Evolución clásica}

En esta pieza, el personaje colectivo, de carácter cómico o farsesco, funciona como rastro de la tradición clásica, donde "la imitación de cualquier acontecimiento de la vida diaria con exageración grotesca" (Burckhardt, 1974: 343) constituye un elemento diegético de la comedia de la Antigüedad Clásica, sobre todo en la de Aristófanes, donde se integra ampliamente a la acción (Pavis, 1998: 97). Precisamente el planteamiento es que este elemento sobre el que pivota el sainete carnavalesco estrenado en 1971 viene a actualizar las bases mismas del teatro. En concreto, es medular la función del coro de la Grecia clásica que, como se sabe, configura un elemento complejo no estático que tuvo diferentes usos, cantidad de miembros, de inserciones, de intensiones y formas de participación (Zimmermann 2012).
Pavis define que en su forma más general, el coro está compuesto de fuerzas no individualizadas y a menudo abstractas que representan intereses morales o políticos superiores (1998: 96). En Las fisgonas de Paso Ancho, esta figura anacrónica aparece replanteada a través del trío de curiosas vecinas, que dan cuenta de la evolución del coro desde una suerte de degradación paródica en sus apreciaciones abundantes en estereotipos, prejuicios, valores -incluso ellas mismas adquieren una figuración preponderante al ser propiciadoras del desencadenamiento mismo de la trama-. Ello tendría relación con el hecho de que se enuncie desde el género de la comedia -lo que reactualiza la idea de Bowra en el sentido de que no constituye un mero apéndice a los restantes actores sino un grupo partícipe de la trama, cuyas aseveraciones participan de la acción dramática y por su poca definición reproducen las diversas reacciones posibles (1968: 179)-.

A través del coro como dramatis persona -o sea que sabe(n) lo mismo que los demás personajes-, la obra de Rovinski plantea no sólo el desencadenamiento de la acción, sino una valoración y un resumen de la situación para ayudar al lector/espectador a dar seguimiento al flujo de sucesos mostrados como un hecho de carácter jocoso, fruto de un mundo imperfecto con el reconocimiento irónico de sus vicios y defectos.

Vecina 1. - Carmencita, si supiéramos más de las vidas de las gentes, cuánta ayuda, cuánto consuelo podríamos aportar las gentes caritativas como nosotras. Desgraciadamente prefieren esconder sus trapitos sucios y no se dejan aconsejar por las personas discretas (Rovinski, 1995: 9).

El coro, que en la tradición griega tiene escasa participación -en frases cortas o a lo sumo un par de versos, nunca una interrupción que se abra en continuidad con el poema (Burckhardt 1974: 349) - se replantea en la obra de Rovinski en virtud de su carácter diegético que adquiere mayor preponderancia, en el sentido de que la situación no sólo es descrita o comentada, 
sino desencadenada por las mismas vecinas, a favor de un subsidio de la acción, esto es, como actualización de la instancia de catalización.

Desde esta posición marginalmente doble (económica y genérica ${ }^{2}$, tiene lugar el denostado lenguaje del fisgoneo o chafardeo, como parte de los mecanismos de actualización del coro. Es el punto desde donde se elabora, según Marcela Lagarde, una representación intelectual de los hechos, una creación de una versión propia, una recreación ideológica del sentido común que se intercambia con los demás sujetos (casi siempre feminizados) y de un saber cuyo poder radica en la distorsión intencional de la realidad apreciada (2005: 348) -aunque aquí lo intencional queda matizado por lo inconsciente o mecánico-. De ahí que, como en Las Euménides de Esquilo o en Las bacantes de Eurípides, "[t]odo cuanto les ocurre a los restantes personajes se ha de juzgar desde la perspectiva del coro, que encuadra debidamente los acontecimientos, los comenta y enjuicia y con frecuencia da una tónica emotiva que condiciona nuestra reacción ante ellos" (Bowra, 1968: 178).

El ejercicio del coro en este caso se conduce por la elaboración y transmisión de un saber asentado en valores dominantes (estereotipados, prejuiciosos, conservadores) pero emitidos desde otro foco. El discurso responde a una pura alucinación que figura la conducta incomprensible del hijo Hernán - cuya descortesía y agresividad familiar es paulatina y gradualmente desplazada por designaciones cada vez más graves: primero vicioso (consumidor de droga), luego bestia salvaje, más tarde masón -como insulto-, hasta finalmente poseso por el demonio- y dada por verdadera por las autoridades oficiales (la policía) y mediáticas (la prensa ${ }^{3}$ ).

Por tanto, el discurso del trío de vecinas termina siendo preceptivo, normativo, pródigo en valoraciones encubiertas. Gira en torno a las funciones, las actitudes de su ser como esposasmadre sen relación con los otros, en sus cuidados y sus favores, de manera que este tipo de pláticas constituyen un rito pedagógico que consiste, como sostiene la antropóloga mexicana, en la transmisión de las pautas, las normas, las reglas de comportamiento social (Lagarde, 2005: 360). En consonancia con las funciones del coro en la Antigüedad Clásica, resulta un elemento agresivo y burlón, sobre todo en la comedia dórica siciliana (Cantarella, 1971: 178). Entre otras instancias, esta burla se vierte aquí sobre la idealización de la relación maternal, uno de los ejes centrales de la parodia de Rovinski-que junto con la hipérbole constituían figuras de la comedia griega-. De tintes estereotipados -que se parodian: es una comedia satírica-, la argumentación de las vecinas se centra en la valoración de las relaciones maternas, en este caso entre los menores -ajenos (como el huérfano vendedor de pejibayes), propios (como Hernán), metaficcionales (como Abelardo)- con las madres ${ }^{4}$.

Hay consonancias que permiten verificar este hecho. En el coro clásico, cada verso prosigue, completa o contradice al anterior en un proceso ágil (Bowra, 1968: 177), en el que "pudo acontecer que uno [de los personajes del coro], más emocionado, se expresase líricamente mientras que el otro hablaba en diálogo corriente, de lo que resultaría un contraste muy significativo, o que dentro del coro mismo el canto se repartiera en voces distintas movidas por sentimientos dispares" (Burckhardt, 1974: 289). Técnicamente en el coro de Rovinski hay una diferenciación de las voces femeninas pero sin desarrollarse de forma individualizada como personajes -a pesar de que respondan a los nombres de Herminia, Carmen y Marielena: bien la instancia discursiva ni siquiera reconoce, únicamente enumera-, y su desempeño es el de un personaje colectivo que hereda la función narrativa de esta antigua y menguada figura griega $^{5}$, si bien no pronuncia el discurso a la vez, sino de manera complementaria, donde las ideas se descomponen separadamente. Tienen su sentido justamente en tanto acotación de un mismo discurso que la actualización induce a separar en personajes específicos, en este caso tres. De ello da cuenta el siguiente fragmento, a la vez que permite distinguir la agilidad sobre la que se construye el ritmo en el que reposa la acción dramática: 
Vecina 3.- Esta juventud de hoy es irrespetuosa Vecina 2.- Inmoral

Vecina 3.- Desafiante de las leyes de Dios

Vecina 2.- Ya no perdonan ni las canas (Rovinski, 1995: 19).

Construcciones de este tipo suponen una dramaturgia moderna donde el replanteamiento del coro se ejecuta inhibido desde el realismo y naturalismo del siglo XIX para no infringir la verosimilitud (Pavis, 1998: 97), o como canalizador de la reflexión crítica desde la ironía en una propuesta moderna -como también, a su manera, lo han hecho Bertold Brecht o Woody Allen- (Zimermann, 2012: 131, 135). Al igual que en estos dos autores, la transición del coro clásico al moderno en Rovinski logra superar el efecto distanciador, situando la acción en presente y recurriendo a la parodia críticahumorística, popular- en el retrato de una sociedad neocostumbrista.

\section{Teatro neocostumbrista}

Para Cortés, Samuel Rovinski es el único representante de la dramaturgia nacional consolidada que se centra en un abandono de los intereses individualistas a favor de un planteamiento de la colectividad (1988: 25), el cual, vertido en la construcción narrativa, dificulta por cierto la distinción tradicional de personajes según su importancia en la trama, que la vuelve más coral. En la sin duda más conocida de sus piezas, la actualización en distantes coordenadas espacio temporales está en función directa con la construcción del hecho principal: un incidente doméstico que trasciende el orden público precisamente por intercesión de las referidas marujas. Rovinski tipifica esta composición social no vernácula -de tintes picarescos en remisión diluida al motivo de la indiscreción ajena de El diablo cojuelo (1641)en el momento en que contextualiza la trama bajo coordenadas propiamente locales: una comunidad popular, de alta densidad y bajo costo diseñada con calles estrechas y moradas aglutinadas que invitan a la intromisión en las intimidades. En ese sentido, Las fisgonas de
Paso Ancho procede a anticipar la elaboración del relato de cotidianidades ajenas en calidad de espectáculo bajo el tamiz de la crítica a las costumbres sociales que perviven de un entorno provinciano. Pese a ello, su acción se inscribe en la urbe contemporánea -la de los suburbios ${ }^{6}$-, de donde la actividad principal es el cotilleo producido, emitido y difundido por las mujeres de extracción popular, de lo que se puede colegir el mantenimiento del estereotipo femenino asociado a la práctica que señalaba Lagarde.

Como parte de una producción literaria que ambienta sus géneros no sólo narrativos en la urbe, la información de la cotidianidad vecinal proviene de la escucha furtiva favorecida por la mencionada cercanía logística de la disposición de los inmuebles. La contigüidad y el material de construcción (madera) de sus viviendas invitan a la ejecución de esa actividad tan típicamente urbana, abocada en este caso menos a la representación de la gratificación personal que podría suscitar la percepción directa de la ilícita actividad (Sanabria 2010) que a la creación del retrato de un neocostumbrismo conducido por ese particular coro.

"Entonces, usted lo ve, nos vemos obligadas a usar los medios más difíciles, las posiciones más incómodas para estar atentas y acudir sin demora en el momento en que nos necesitan" (Rovinski, 1995: 9), termina su argumentación la citada vecina, aludiendo a un fisgoneo no panorámico (visual) como el diablo cojuelo, que levantaba los techos de las casas, sino de contigüidad primeramente acústica: precisamente el motivo de las casas por dentro era un tema costumbrista bastante común en las primeras décadas del siglo XIX, con precedentes en la literatura española como la novela de Luis Vélez de Guevara. Como pieza de tales características, Las fisgonas de Paso Ancho contiene una suerte de hibridación de las dos primeras formas de mediación en el ámbito de las evoluciones semióticas de la vida cotidiana partiendo de abstracciones sociales económicas (Zeledón 1997). Dominado, en un primer estadio -la aldea-, por una economía de trueque, las prácticas comunicativas se fundamentan en la circulación de la oralidad. No obstante, en la 
obra de Rovinski ya se ha empezado a producir el desplazamiento de los emisores privilegiados, que también se apoyan -como sería de esperar en un modelo por lo demás imposible de purezaen la vicaría de la trascendencia (el cura). Ciertamente la estructura confesional tiene algo de peso en la comunidad y convive con la legitimación de los medios de difusión de masas, que en teoría se corresponderían a una fase de mayor evolución, de economía de consumo capitalista -la urbe-. De ello da cuenta la transmisión dominante del discurso televisivo (las telenovelas Simplemente María, El hijo pródigo, la serie Hospital Central) y radial (la emisora Universal).

El emplazamiento de este barrio popular en los suburbios, su proceso inacabado de integración a la modernidad trasluce la persistencia de una comunidad de una base previa, rural, a lo que habría, por lo demás, de aunársele el efecto de marginalidad social -dado por la distancia con el lector/espectador que siempre impone la ficción-. Y las formas de comunicación se centran en la oralidad de la cotidianidad como alternativa de resistencia a los noticiarios, para el caso, del canal 7: ante su aburrido visionado (virtual, mediado) se hace preferible la invención de la noticia (real, inmediata) y con valor añadido del morbo porque los sujetos que participan son conocidos y concretos.

El origen procede de una actividad acústica que, con el componente imaginario ${ }^{7}$, se proyecta, es más, alimenta valores dominantes y se anticipa a lo que en el panorama mediático -no ya radiofónico sino televisivo- se conocería como el reino de los cualquiera, aunque sin la singularidad propia de los actores destacados. Frente a éstos -las habituales celebridades que llegan a suscitar un considerable interés alrededor de sus rutinas-, John Langer habría, 30 años después, de hacer extensiva la condición de noticiable a gente común a la que se le cede espacio por su capacidad de realizar, inversamente, acciones extraordinarias en su entorno inmediato (2000: 72-74). Es evidente que Langer no se refería a los sucesos de barrio que más adelante darían lugar a los espectáculos de telerrealidad, pero ciertamente la escogencia mediática de la noticia no deja de cubrir una no aleatoria selección de las individualidades y actividades emergidas de los sectores populares. Y éstos se expresan bajo la elaboración de formas de choque -un conflicto familiar-, lo cual representa una excedencia al orden habitual y por tanto su inscripción como hecho noticiable -máxime si se transmite en formato directo, que agrega valor a su contenido-.

Se trata, en suma, de una práctica colectiva, compartida a nivel gregario y cuyas resonancias en el resto de la población dan pie a su empoderamiento -al punto tal de dar título a la obra-. La escucha orientada, prácticamente predirigida, se procesa, se adecua, ajustándose a prejuicios, a elucubraciones mentales y valores -formados por contraste u oposición (como mecanismo discursivo de la ironía que atraviesa la comedia) entre la representación de los modelos filiales: el idílico de Abelardo, el hijo pródigo, y el demoníaco de Hernán, el hijo rebelde-.

Y de la furtiva actividad se genera la impresión de transformación de la realidad por quienes se mantienen en posición de debilidad social y política en la participación de los complicados mecanismos del poder (Lagarde, 1995: 354). A ese respecto, en una de sus primeras novelas, Javier Marías consignaba a través de su protagonista narrador el término to eavesdroper en alusión a la atención acústica de lo indiscreto como ejercicio premeditado, en contraste con lo que él mismo reconocía bajo el también anglicismo de to overhear, a saber, un acto menos deliberado, más accidental. Justamente, la actividad del eavesdroper constituye una forma primitiva "de obtener la información precisa para no ser un marginado de los que no poseen ni transmiten ninguna" (1993: 200201), que la literatura universal reserva para el caso de los humildes personajes femeninos de Rovinski que se mantienen al margen del conflicto, tradicionalmente reducidos, como en el género de la picaresca, a telón de fondo. 


\section{Dinámica refleja}

Asimismo, la reactualización de esta figura clásica permite canalizar la puesta en escena de al menos dos representaciones -en otras palabras, una suerte de teatro dentro del teatro, al estilo de una mise en abyme-, como al final viene a sugerirse por las mismas vecinas, para las que el valor como espectáculo priva sobre el eventual ideal del afán al servicio público atrás mencionado:

Vecina 3.- ¿Qué tal si a Herminia no se le ocurre pegar la oreja a la puerta de los Alfaro?

Vecina 1.- ¿Qué está queriendo insinuar, Marielena? Vecina 3.- Pues que tal vez nos habríamos perdido el teatro de esta noche (Rovinski, 1995: 46).

El fisgoneo no culmina en la obra, la trasciende y se revierte a la práctica del género mismo, como concluyen Rojas y Ovares: "Así como nosotros, espectadores, contemplamos la acción dramática, ellas [las vecinas] observan a través de las ventanas lo que sucede en el interior de las casas. Pero su actividad no se limita a una observación pasiva pues inmediatamente lo visto es interpretado en la forma como ellas mismas lo entienden [...] Lo que las vecinas están observando se convierte en una especie de obra que sucede dentro de la casa. Los espectadores, a su vez, las están viendo a ellas" (1995: 195²). Tratándose de la puesta, los receptores (espectadores) reproducen una actitud paralela de escucha -como el coro, esto es, como las vecinas-, en un nivel metaficcional. La atención simultánea está centrada en la acústica antes que en lo visual que mueve con posterioridad a asomarse por la ventana para apurar la percepción y dar forma y sentido a la historia, es decir, la visión se activa para complementar lo oído. Pero el término fisgonear tiene otra acepción, fisgar -husmear con el olfato-, hecho que incorpora un nuevo sentido de percepción de contacto (al gusto y tacto). Estos sentidos considerados menores suponen la disminución de la proximidad física con el objeto de interés, a diferencia de los mayores (el oído y sobre todo la visión, es decir, aquellos que instauran una distancia mayor) (Metz, 1979:
58), que se formaliza en el arte y en concreto con la escena teatral. Así pues, metafóricamente la obra refuerza la propensión animal del acto perceptivo que en la construcción de la historia habrá de acabar incorporando el componente imaginativo, inventivo.

A eso se aboca la trama, a la complementación de formas de percepción en la búsqueda de historias. Los personajes encuentran extensión en los receptores, las fisgonas hallan la prolongación de su acto en el lector/espectador-que precisamente en esos momentos en cualquiera de sus dimensiones, también se encuentra atisbando-, como práctica inherente al género y a la ficción en general, intimidades ajenas. Es la esencia misma de la representación, formalizada por la renovación conceptual, estructural e histórica de una figura elaborada en el teatro clásico como coro, que asiste a los acontecimientos que atestigua, mayormente conmovido -en su sentido etimológico, patético en su sentido etimológico, esto es, en tanto emoción íntima en este caso mediada por el exceso paródicoe indiscreto, que relata y recrea los vicios privados de las costumbres arraigadas en la ruralidad de la urbe, si es que se le puede llamar así a la provinciana capital.

\section{Notas}

1. No hay que desatender que la obra se enmarca en un contexto específico del teatro costarricense, de puestas en escena de obras de fácil montaje, como esfuerzo del Teatro Universitario, en el marco de los festivales universitarios desarrollados en 1968 y 1971 patrocinadas por el Consejo Superior Universitario (CSUCA) (Bell y Fumero, 2000: 34).

2. A la luz de una función narrativa personificada por tradición en la doble vulnerabilidad del género (femenino) y condición social (esclava): Scherezade.

3. De esta serie de regulaciones informales y tácitas sobresale el aparato policial personificado en los desmañados guardias, pero que más ampliamente ha sabido profesionalizarse bajo el espionaje como una forma de coerción social -por lo demás, de 
abundantísima producción social y artística-. En el apersonamiento de la autoridad en Paso Ancho, uno de los guardias lanza una artificiosa admonición a Hernán. Lo hace desde un tono coloquial que se va transformando en melodramático, como da cuenta el rebuscamiento sintáctico y léxico de alta semejanza, de efecto antitético con el no menos codificado discurso telenovelesco que conmueve a las inmovibles fisgonas: "Guardia 1.- Aproveche su última oportunidad, amigo. No sea terco. De nada le servirá. Vea, apelo a sus sentimientos. ¿No se da cuenta de que se trata de su madre, de que es una santa la que sucumbe en estos momentos bajo sus garras, de que es un impulso diabólico el que guía esas fatídicas y crueles manos? A la madre no se le pega. La que nos dio la vida, la que se sacrificó por nosotros, la que marchitó su dulce juventud para educarnos, para darnos el alimento, para darnos el vestido. Ella. Santa ella, es la que merece nuestro respeto y veneración. Suelte su cuello, contemple las manos asesinas y llore por el error cometido" (Rovinski 1995: 26).

4. El coro ha sido desde sus orígenes inseparable de la música. Si bien las didascalias no indican que, como parte de las funciones tradicionales del coro sus miembros bailen, éstas sí cantan -la canción hagiográfica laica de Abelardo-, al igual que otros personajes como el vendedor o los miembros de la policía.

5. En la tragedia griega inició con 12 miembros y aumentó a 15 con Sófocles, mientras que en la comedia era de 24 (Petrie 1946: 160) y la actualización de Rovinski ha propiciado la reducción a tres.

6. Para la práctica visual, el lenguaje costarricense ha acuñado el verbo 'samuelear', que no se ajustaría a la actividad visual del drama de Rovinski, por cuanto se supone más propia del género masculino -el Diccionario de la Lengua Española lo define como contemplar o tratar de ver los muslos o partes sexuales a una mujer-. Más bien, la obra se adecua a la reproducción de cánones tradicionales donde el desencadenante es el equivalente femenino.

7. Esto es, sin otra constatación fuera de la interpretación acuciada por el visionado televisivo (telenovelesco).

8. La crítica privilegia el sentido visual y olvida que inicia cuando una vecina encuentra a otra afinando el oído tras la puerta. Confusiones de este tipo responden al peso tan categórico de la escoptofilia en la cultura occidental -por lo privilegiado, a partir de los griegos, del más noble de los sentidos-.

\section{Bibliografía}

Bell, Carolyn y Fumero, Patricia (eds.). 2000. Drama contemporáneo costarricense: 1980-2000. San José, Costa Rica: Editorial de la Universidad de Costa Rica.

Burckhardt, Jacob. 1974. Historia de la cultura griega. Vol. III. Barcelona: Iberia.

Bowra, C. M.. 1968. Introducción a la literatura griega. Madrid: Guadarrama.

Cantarella, Rafaele. 1971. La literatura griega clásica. Buenos Aires: Losada.

Cortés, María Lourdes. 1998. "En torno a la producción de sentido de los textos dramáticos de Cañas, Gallegos y Rovinski”, Káñina, Revista de Artes y Letras de la Universidad de Costa Rica, Vol XII (1): 19-33.

Cuvardic García, Dorde. 2006. "El tema de las casas por dentro: de 'El Diablo Cojuelo' a los artículos de costumbres, el cómic y el cine", Káñina, Revista de Artes y Letras de la Universidad de Costa Rica, Vol. XXX (1): 117-131.

Gómez Redondo, Nicolás. 1994. El lenguaje literario. Teoría y práctica. Madrid: Edaf.

Lagarde y de los Ríos, Marcela. 2005. Los cautiverios de las mujeres: madresposas, monjas, putas, presas y locas. $5^{\mathrm{a}}$ Ed.. México: UNAM.

Langer, John. 2000. La televisión sensacionalista. Barcelona: Paidós. 
Marías, Javier. 1993. Todas las almas. Barcelona: Anagrama.

Pavis, Patrice. 1998. Diccionario del teatro. Barcelona: Paidós.

Petrie, A.. 1946. Introducción al estudio de Grecia. Historia, antigüedades y literatura. México: Fondo de Cultura Económica.

Quesada, Álvaro. 1999. "La dramaturgia costarricense de fin de siglo", Memoria del VIII Congreso de Filología, Lingüística y Literatura Carmen Naranjo: 1-10.

Metz, Christian. 1979. El significante imaginario. Barcelona: Gustavo Gili.

Rojas, Margarita y Ovares, Flora. 1995. 100 años de literatura costarricense. San José, C.R.: Farben.

Rovinski, Samuel. 1995. Las fisgonas de Paso Ancho. San José, C.R.: Editorial Costa Rica.
Sanabria, Carolina. 2011. Contemplación de lo intimo. Lo audiovisual en la cultura contemporánea. Madrid: Biblioteca Nueva.

Vargas Vargas, José Ángel y Vásquez Vargas, Magdalena. 1987. Las fisgonas de Paso Ancho y El martirio del pastor. Dos perspectivas de la obra dramática de Samuel Rovinski, Tesis para optar al grado de licenciatura en Filología Española, Universidad de Costa Rica.

Vélez de Guevara, Luis. 1989. El diablo cojuelo. $2^{a}$ Ed. Madrid: Cátedra.

Zeledón, Mario. 1997. "Evolución semiótica de las mediaciones: una voz, mundos múltiples", ponencia en el II Congreso Centroamericano de Antropología, Guatemala.

Zimmermann, Bernard. 2012. Europa y la tragedia griega. De la representación ritual al teatro actual. Madrid: Siglo XXI.

\section{() $(\Theta \Theta \Theta$}

Este obra está bajo una licencia de Creative Commons

Reconocimiento-NoComercial-SinObraDerivada 4.0 Internacional. 